\title{
Too few beds
}

\author{
J.P. Watson
}

The avallability and use of beds for acute psychiatric admissions has become the most pressing problem in many of today's mental health services, and warrants urgent and wide consideration.

The problem has three day-by-day manifestations: it is too often impossible to admit patients when they need urgent admission; it is too often necessary to discharge patients before they should be discharged; and the in-patient environment is nowadays too often aversive for patients and also for staff. Acute wards are reminiscent (to those with long clinical memories) of observation wards, those disturbed and varied reception units to which acutely disordered individuals were taken for triage and then transfer to where the treatment was; but today's wards are the treatment. On the personal criterion of "would I be prepared to have one of my relatives admitted to this ward", too many acute wards are simply unacceptable.

A major part of this state of affairs is that there are too few beds. Bed occupancies are regularly in excess of $100 \%$. Patients in the community who have crisis relapse often do not have the choice of admission even for a short time, which is not at all the same as choosing to have home treatment. At the same time, there is pressure to admit mentally disordered offenders inappropriately located in the criminal justice system. Courts often require longer lengths of stay than have become customary, with massive implications for bed usage. Further problems arise from having to admit everyone to the same ward. With increasing levels of ward disturbance, psychosomatic and most liaison patients, some organically ill patients, and many depressed or anxious individuals, often find today's wards uncongenial or worse. The long-known advantages of different environments appear to have been lost.

In the rush to reduce hospital expenditure, the pendulum has swung too far from the residential aspects of acute treatment. Exciting developments might examine the possibility of developing varied acute residential environments to complement hospital beds - a range of "wards in the community' which could recreate the best of the old asylums. But without sufficient 'beds' of some sort, modern mental health care will simply become impossible in many places. Hollander \& Slater's paper (pages 532-534) is a helpful contribution to a vital debate.

J.P. Watson, Professor of Psychlatry, UMDS, Guy's Hospital, London SE1 9RT 